\title{
Solid-phase cross-metathesis: the effect of the non-immobilized olefin and the precatalyst on the intrasite interference
}

\author{
Andrés A. Poeylaut-Palena and Ernesto G. Mata* \\ Instituto de Química Rosario (CONICET - UNR), \\ Facultad de Ciencias Bioquímicas y Farmacéuticas, Universidad Nacional de Rosario, Suipacha \\ 531, 2000 - Rosario, Argentina \\ E-mail: mata@iquir-conicet.gov.ar
}

\section{Dedicated to Prof. Benito Alcaide on the occasion of his 60th anniversary}

DOI: http://dx.doi.org/10.3998/ark.5550190.0011.319

\begin{abstract}
We have developed a study on the factors that influence the intrasite interactions in the crossmetathesis on solid support. When such interactions are possible, the outcome of the intrasite byproduct depends on the non-immobilized olefin and the precatalyst used. The comparatively poor reactivity of first generation Grubbs precatalyst makes the easier intrasite coupling to succeed.
\end{abstract}

Keywords: Cross-metathesis, solid-phase synthesis, organometallics

\section{Introduction}

The increasing progress in biological screening allows the analysis of large number of compounds in a short period of time. To meet that demand of molecules, synthetic techniques aimed to increase in number, diversity and complexity of the compounds obtained have gained interest in both industry and academia. ${ }^{1}$

For more than a decade, solid-phase organic synthesis (SPOS) has evolved from the chemistry of peptides and oligonucleotides to find application in almost every area of synthetic research. Due to the central role of organometallics in modern organic synthesis, their encounter with SPOS was obvious from the very beginning. Thus, solid-phase variants of classical organometallic reactions, such as Stille, Heck, Suzuki and Sonogashira couplings, were soon established as well recognized reactions. ${ }^{2}$

However, there are some solid-phase organometallic reactions that have not yet reached their mature state. Cross-metathesis on solid support represents a very interesting alternative to more traditional carbon-carbon bond forming reactions. Starting materials in cross-metathesis require 
little synthetic effort in their preparation compared to stannanes, halides and boronates, necessary for Stille, Heck and Suzuki reactions. Carbon-carbon double bond is a ubiquitous functional group present in many natural products. Furthermore, the development of a new generation of olefin metathesis precatalysts ensures mild reaction conditions, together with an impressive functional group tolerance, high activity and stability. Probably the major drawback of solutionphase cross-metathesis is the difficulty of avoiding the formation of unwanted homodimeric products (Scheme 1a). ${ }^{3}$ In principle, linking one of the olefins to a polymer has some potential advantages. The non-immobilized olefin can be added in excess in order to complete the reaction and the homodimer that remains is solution can be eliminated easily by filtration, preventing time-consuming separation techniques. Additionally, under certain conditions, homodimerization of the immobilized olefin is a less favorable process due to the site isolation on the polymeric matrix (Scheme 1b). Ruthenium contamination of synthetic products ${ }^{4}$ is another less important issue in solid-phase metathesis.

a)

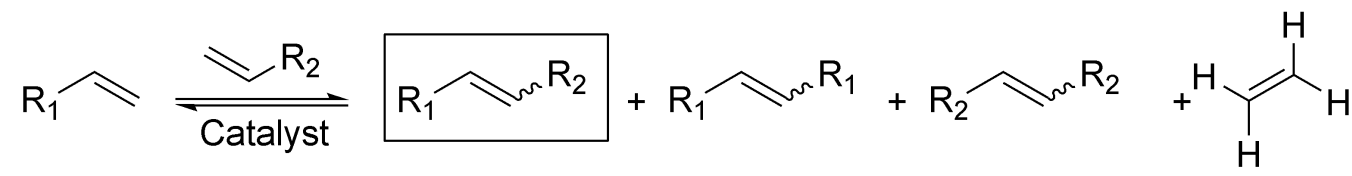

b)

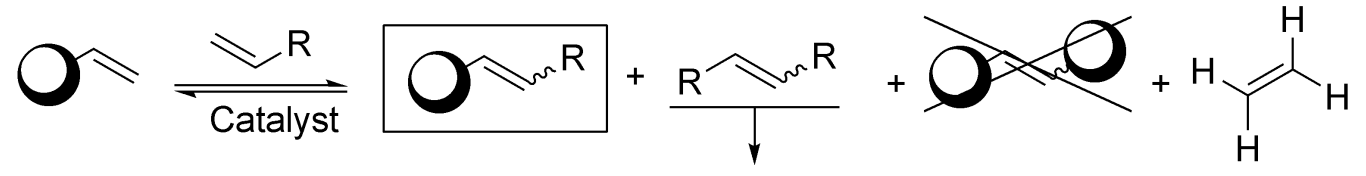

\section{Scheme 1}

Hovewer, and despite its enormous potential, few example of alkene cross-metathesis on solid-phase can be found in the literature and the research in the area is far to be complete. The first generation Grubbs precatalyst 1 (Figure 1), ${ }^{5}$ was scarcely used and with limited success in the initial reports in this area. ${ }^{6}$ The increase in activity from $\mathbf{1}$ to those of the second generation, such as 2 and 3 (Figure 1), ${ }^{7}$ has enhanced the possibilities of an effective application of olefin cross-metathesis on solid support. ${ }^{8}$ Particularly, we have recently studied the role of the homodimerization of the non-immobilized olefin on the reaction outcome. ${ }^{8 \mathrm{~d}} \mathrm{We}$ have demonstrated that solid-phase cross-metathesis using precatalyst $\mathbf{2}$ depends on the degree of homodimerization of the non-immobilized olefin, that is usually added in excess. If an olefin with high propensity to homodimerize is used, the reaction outcome depends on the reactivity of that homodimer; for instance, fast homodimerization to generate an unreactive dimer generally led to a low yield of the desired product. On the other hand, if the homodimerization is slow, high yields of the product is obtained thanks to the excess of monomer used and the conservation of the precatalyst that is not consumed in unproductive cross-metathesis cycles. 


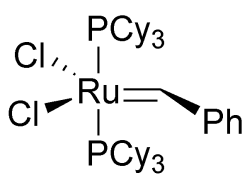

1

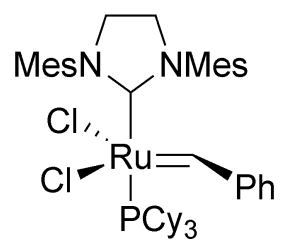

2

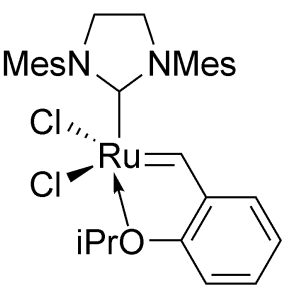

3

\section{Figure 1}

In this paper, we describe further development in order to increase the understanding of the solid-phase version of olefin cross-metathesis.

\section{Results and Discussion}

An interesting issue to address in solid-phase cross-metathesis is the competition of the "intrasite" or "site-site" reaction, which is the reaction of two immobilized molecules linked to the same resin bead. During the course of a previous study, ${ }^{8 \mathrm{~d}}$ we noted some disappointed results when the resin-bound pentenoic acid (4) was used as the immobilized olefin (Scheme 2a). Under the optimized conditions, we found that 4 reacted with an excess of the model non-immobilized olefin 6a (5 eq) and the precatalyst $2(5 \mathrm{~mol} \%)$ in DCM reflux for $20 \mathrm{~h}$ to give, after releasing from the resin and esterification with diazomethane, the expected product 10a in low yield, mostly due to the presence of the 4-octenedioic acid dimethyl ester (11) that corresponded to the intrasite olefin cross-metathesis. In fact, when resin $\mathbf{4}$ was treated with the precatalyst $\mathbf{2}$ in absence of olefin $\mathbf{6 a}$, the homodimeric product 11 was obtained in $85 \%$ yield. Conversely, when similar conditions were applied to the reaction of the immobilized olefin $\mathbf{5}$ and allyl benzene (6a), the desired product 13a was obtained in excellent yield (86\%) as the only detectable

product (Scheme 2b). Considering that both immobilized olefins were obtained from a Wang resin with the same loading level $(1.1 \mathrm{mmol} / \mathrm{g})$, this result can be rationalized as a consequence of the difficulty of $\mathbf{5}$ to homodimerize due to the poor flexibility of the styrene moiety. 
a)<smiles>C=CCCC(=O)OCc1ccccc1</smiles>

4<smiles>C=Cc1ccc(C(=O)OCCOCCO)cc1</smiles>

5 i)

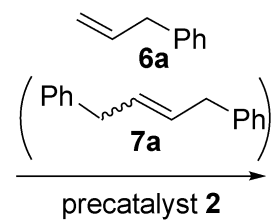<smiles>COC(=O)CC/C=C\CCC(=O)OCc1ccccc1</smiles>

9<smiles>O=C(CC/C=C/Cc1ccccc1)OCc1ccccc1</smiles>

8a<smiles>C=CC[Pb](=O)c1ccccc1</smiles><smiles>COC(=O)CC/C=C/Cc1ccccc1</smiles>

10a<smiles>COC(=O)CC/C=C/CCC(=O)OC</smiles>

iii) $\underset{\mathrm{CH}_{2} \mathrm{~N}_{2}}{\stackrel{\text { TFA }}{\longrightarrow}}$<smiles>COC(=O)c1ccc(/C=C/Cc2ccccc2)cc1</smiles>

\section{Scheme 2}

In order to broaden the study on the cross-metathesis of the immobilized olefin $\mathbf{4}$ and to establish the scope of the intrasite interference, we decided to test the coupling with different non-immobilized olefins (Table 1). Highly reactive type-I olefins ${ }^{3}$ undergo fast homodimerization and their homodimers are still capable to participate in further CM reactions. Examples of this olefin type are allyl benzene (6a) and 4-vinylbenzyl chloride $(\mathbf{6 b}){ }^{8 \mathrm{~d}}$ When resin 4 reacted with these olefins (entries 1 and 2), the corresponding cross-coupled products were obtained in low yield mainly due to the site-site interaction that led to the homodimer $\mathbf{1 1}$.

However, when we used less reactive type-II olefins, such as 2-bromo styrene (6c) and crotonic acid (6d), which suffer from slow homodimerization, the interference of the intrasite reaction was negligible (entries 3 and 4). Finally, gem-disubstituted, non-immobilized olefins, such as $\beta$-pinene (6e) and linonene oxide (6f), were tested (entries 5 and 6). Homodimerization of these low reactive, type-III olefins is not possible, but in both cases no coupled product was detected and the intrasite homodimer $\mathbf{1 1}$ was obtained in very high yield (85\%). 
Table 1. Solid-phase olefin cross-metathesis by precatalyst 2 on immobilized olefin $\mathbf{4}^{\mathrm{a}}$

\begin{tabular}{|c|c|c|c|c|c|}
\hline Entry & $\begin{array}{c}\text { Non- } \\
\text { immobilized } \\
\text { olefin } \\
\end{array}$ & $\begin{array}{c}\text { Homo- } \\
\text { dimerization }\end{array}$ & Product & $\begin{array}{c}\mathbf{1 0} \\
\text { Yield }(\%)\end{array}$ & $\begin{array}{c}\text { 11, } \\
\text { Yield }(\%)\end{array}$ \\
\hline 1 & & $\begin{array}{c}\text { yes, } \\
\text { in } 15 \mathrm{~min}\end{array}$ & & 18 & 70 \\
\hline 2 & & $\begin{array}{c}\text { yes, } \\
\text { in } 20 \mathrm{~h}\end{array}$ & & 45 & 35 \\
\hline 3 & & No & & 87 & 0 \\
\hline 4 & $6 d$ & No & & 100 & 0 \\
\hline 5 & & No & & 0 & 85 \\
\hline 6 & & No & & 0 & 85 \\
\hline
\end{tabular}

${ }^{a}$ Conditions: (i) free olefin 6a-f (5 eq), precatalyst 2 (5 mol\%), DCM, reflux 20 h; (ii) 10\% TFA in DCM at r.t. for $1 \mathrm{~h}$; (iii) $\mathrm{CH}_{2} \mathrm{~N}_{2}$ in $\mathrm{DCM}$ at $0^{\circ} \mathrm{C}$ for $30 \mathrm{~min}$;

These interesting results can be rationalized as follow: under the reaction conditions, a large number of metathesis events are occurring when a very reactive non-immobilized olefin (i.e.: $6 \mathbf{b}$ ) reacts with an also very reactive immobilized olefin, like 4 , including the coupling between two molecules of the same olefin, the cross-coupling between one monomer and one homodimer or two different homodimers (Scheme 3); ${ }^{9}$ however, since the immobilized olefin 4 could be considered as highly concentrated and unable to be diluted, the intrasite reaction is expecting to prevail in the detriment of the hetero-coupling outcome. 


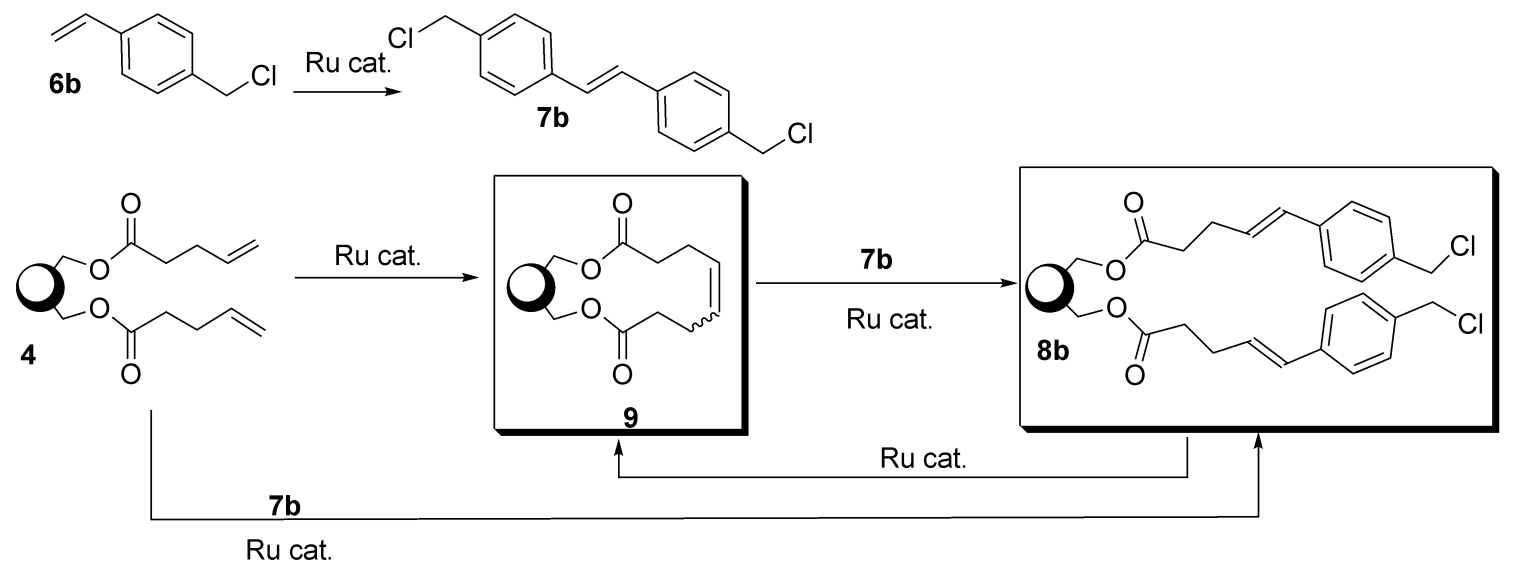

\section{Scheme 3}

On the other side, when a less reactive non-immobilized olefin (i.e.: $\mathbf{6 c}$ ) reacts with the very reactive immobilized olefin $\mathbf{4}$, the cross-coupling reaction generates an unreactive immobilized olefin (8c) that prevents further reactions avoiding the outcoming of the intrasite product (Scheme 4).
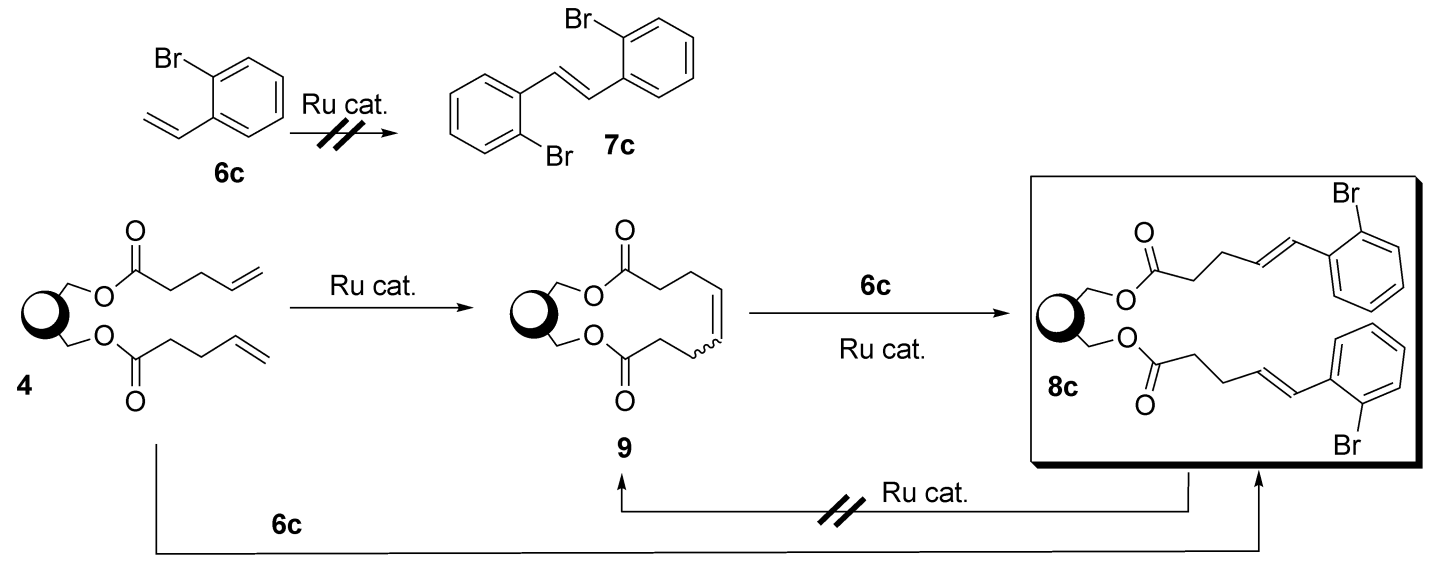

Ru cat.

\section{Scheme 4}

Finally, we expected that very unreactive alkenes (i.e.: 6e), which do not undergo homodimerization at all, would facilitate the formation of the cross-coupled product by forming the unreactive immobilized olefin (8e). However, olefin 6e did not react with the supported substrate $\mathbf{4}$ and the intrasite product was clearly favored (Scheme 5). 


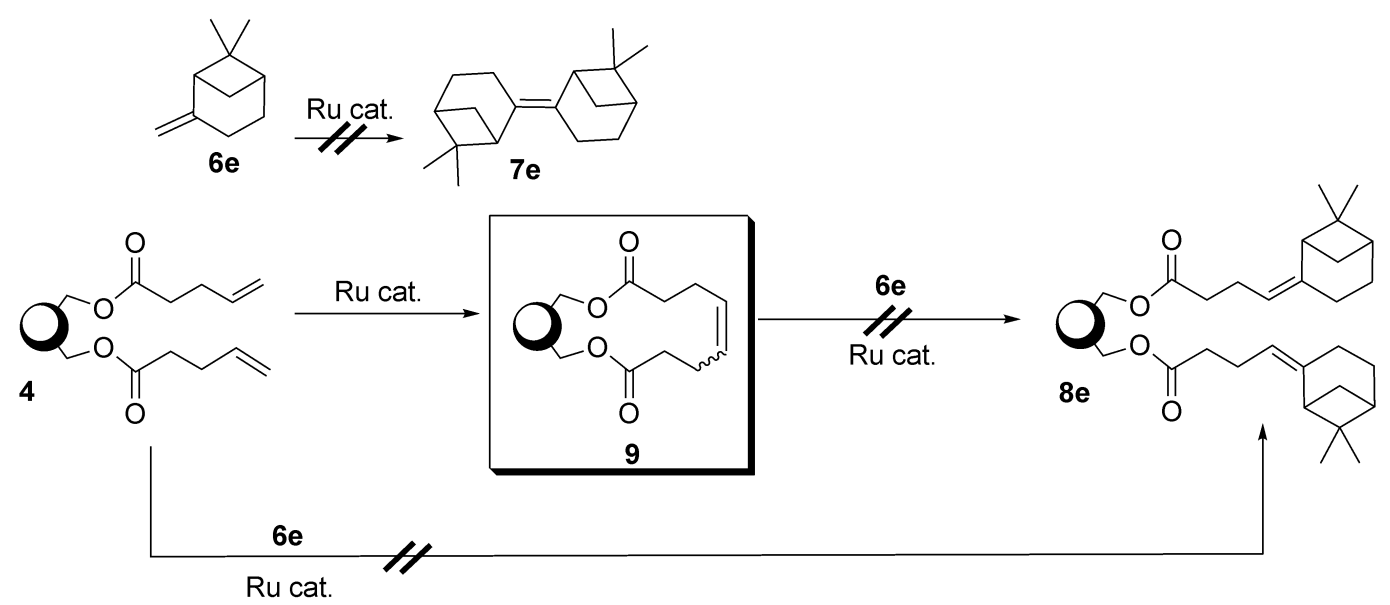

\section{Scheme 5}

The role of the precatalyst's nature in the intrasite interference was also considered. A comparison between the first generation Grubbs precatalyst $\mathbf{1}$ and its second generation counterpairs $\mathbf{2}$ and $\mathbf{3}$, is depicted in Table 2. About the coupling of $\mathbf{4}$ with a type-I nonimmobilized alkene like 6b, precatalyst 1 was even less efficient than 2 and 3 (entries 1-3). Under catalysis with ruthenium complex $\mathbf{1}$, cross-coupled product $\mathbf{1 0 b}$ was obtained in lower yield (14\%) with increasing amounts of the intrasite by-product 11 (70\%) (entry 1). Scheme 3 can also help us to understand the behavior of precatalyst 1. Due to its poor reactivity, the predominant reaction was the intrasite coupling of $\mathbf{4}$ to give $\mathbf{9}$, which is the only metathesis performed between two highly reactive double bond moieties. This result is in agreement with initial reports in solid-phase cross-metathesis where the site-site products were obtained using precatalyst 1. ${ }^{6 a}$ Probably, the poor reactivity of this precatalyst that favor the intrasite reaction, could explain the lack of interest in this kind of cross-metathesis for more than a decade. 
Table 2. Solid-phase olefin cross-metathesis on immobilized olefin 4 using different precatalysts $^{\mathrm{a}}$

Homo-
dimerization precatalyst

${ }^{a}$ Conditions: (i) free olefin $\mathbf{6 b}, \mathbf{c}(5 \mathrm{eq})$, precatalyst 1-3 (5 mol\%), DCM, reflux 20 h. (ii) $10 \%$ TFA in DCM at r.t. for $1 \mathrm{~h}$, (iii) $\mathrm{CH}_{2} \mathrm{~N}_{2}$ in DCM at $0^{\circ} \mathrm{C}$ for 30 min. ${ }^{b}$ After $20 \mathrm{~h}$ under our crossmetathesis reaction conditions, homodimerization occur with $30 \%$ conversion.

When we used the less reactive type-II olefin 2-bromo styrene (6c), precatalyst 1 gave the intrasite by-product 11 in very high yield (83\%) and a minor amount of the desired olefin 10c (6\%) (entry 4). On the other hand, precatalyst 2 gave the cross-coupled product 10c as the only detectable product (entry 5). While in both cases homodimerization of the non-immobilized olefin $\mathbf{6 c}$ is very slow, precatalyst $\mathbf{2}$ generates the unreactive immobilized olefin $(\mathbf{8 c})$ that prevents further reactions (Scheme 4). For precatalyst 1, explanation is the same as before: the only metathesis performed between two highly reactive double bond moieties is the intrasite homocoupling.

Interestingly, precatalyst 3 gave mixture of 10c and the by-product 11 (entry 6). This precatalyst is the only one that gives some homodimerization of the olefin $\mathbf{6 c}$. The higher activity of $\mathbf{3}$ can explain the reaction outcome. As a consequence of such reactivity, the immobilized cross-coupled product $\mathbf{8 c}$ can, at least in part, react again with catalyst $\mathbf{3}$ to give the intrasite olefin $\mathbf{9}$, which is not possible with the other precatalysts (Scheme 6). 


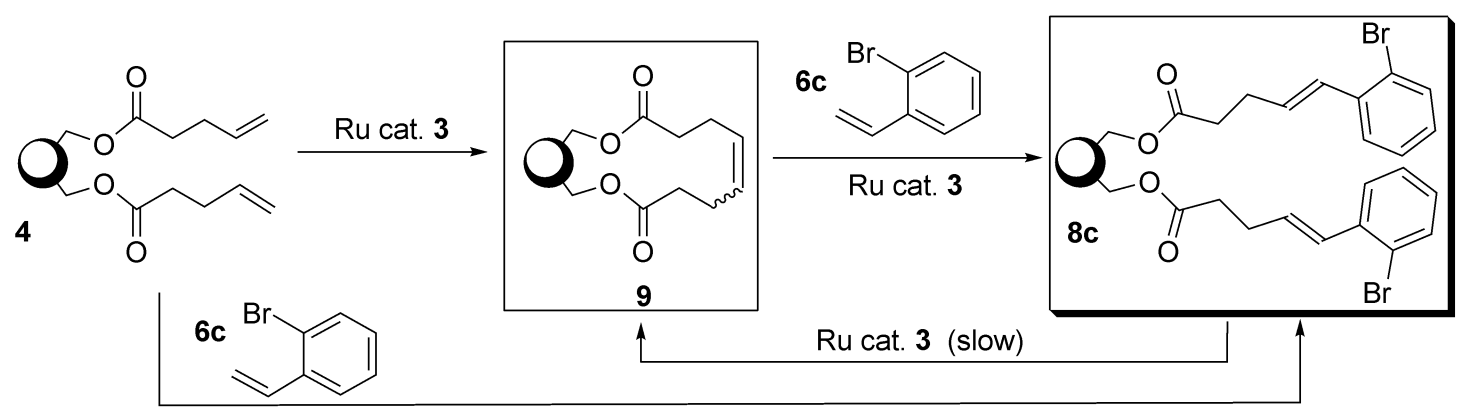

Ru cat. 3

Scheme 6

\section{Conclusions}

The lack of success of first generation Grubbs precatalyst (1) in solid-phase cross-metathesis has caused a delay in the development of the solid-phase cross-metathesis. As a consequence of the evolution of ruthenium precatalysts to more active species such as $\mathbf{2}$ and $\mathbf{3}$, a renaissance of this potentially interesting area of research has just begun. In this work, we report our conclusion about the factors that influence the intrasite interactions in the cross-metathesis on solid support. Using a support such as Wang resin with a standard loading level (about $1 \mathrm{mmol} / \mathrm{g}$ ), the capacity of generating intrasite products depends on the length of the attached moiety and its flexibility (compare resin 4 and 5, Scheme 2). If the site-site interactions are possible, the outcome of the intrasite by-product will depend on the non-immobilized olefin used. Generally speaking, highly reactive type-I, easily homodimerizable olefins are expected to give high yield of the intrasite product; while type-II olefins, with slow homodimerization, usually give no intrasite outcome and high yield of the desired product, due to the formation of an unreactive heterocoupled moiety on the resin. With even less reactive, gem-disustituted olefins the easier intrasite homocoupling prevails. The effect of the precatalyst used on the site-site interference is also very clear. The comparatively poor reactivity of first generation Grubbs precatalyst (1) makes the easier intrasite coupling to succeed. This study shed light on the factors involved in the process for a better understanding of the solid-phase cross-metathesis and gives a support to its application to the synthesis of libraries of biologically interesting molecules.

\section{Experimental Section}

General Procedures. Chemical reagents were purchased from commercial sources and were used without further purification unless noted otherwise. Solvents were analytical grade or were purified by standard procedures prior to use. Infrared spectra (IR) were recorded on a Shimadzu Prestige 21 spectrophotometer and only partial spectral data are listed. ${ }^{1} \mathrm{H}$ NMR spectra were 
recorded on a Bruker avance at $300 \mathrm{MHz}$ in $\mathrm{CDCl}_{3}$, in the presence of TMS (0.00 ppm) as the internal standard. ${ }^{13} \mathrm{C}$ NMR spectra were recorded on the same apparatus at $75 \mathrm{MHz}$ with $\mathrm{CDCl}_{3}$ as solvent and reference (76.9 ppm). ${ }^{13} \mathrm{C}$ NMR assignments were made on the basis of chemical shifts and proton multiplicities (from DEPT spectra). Analytical thin-layer chromatography (TLC) was carried out with silica gel $60 \mathrm{~F}_{254}$ pre-coated aluminum sheets (Merck). Flash column chromatography was performed using Merck silica gel 60 (230-400 mesh). Wang $\left(\mathrm{C}_{\mathrm{T}}=\right.$ $1.1 \mathrm{mmol} / \mathrm{g}$ ) resin was purchased from Novabiochem (San Diego, CA, U.S.A.).

\section{General procedure for the solid-phase cross-metathesis by ruthenium carbene complexes.}

Resin-bound olefin (4) (163 mg, $0.92 \mathrm{mmol} / \mathrm{g}, 0.15 \mathrm{mmol})$ was suspended in anhydrous DCM $(10 \mathrm{ml})$ and the non-immobilized olefin $(\mathbf{6 a}-\mathbf{f})(0.75 \mathrm{mmol}, 5.0 \mathrm{eq})$ was added via syringe under a nitrogen atmosphere. The precatalyst (1-3) $(7.5 \mu \mathrm{mol}, 5 \mathrm{~mol} \%)$ was added and the flask was fitted with a condenser and refluxed for $20 \mathrm{~h}$, after which the resin was filtered, washed with DCM ( $3 \times 4 \mathrm{~mL}), \mathrm{MeOH}(3 \times 4 \mathrm{~mL}), \mathrm{DCM}(1 \times 4 \mathrm{~mL})$, and dried under high vacuum. The resin was resubjected to the same reaction conditions. Resin-bound olefin $(\mathbf{8 a}-\mathbf{f})(0.15 \mathrm{mmol})$ was treated with $5 \mathrm{~mL}$ of $10 \%$ TFA in DCM for $1 \mathrm{~h}$. The mixture was filtered and the filtrate was evaporated under reduced pressure to give the crude product. This crude material was dissolved in DCM and treated with diazomethane at $0^{\circ} \mathrm{C}$ for $30 \mathrm{~min}$. The solvent was evaporated under reduced pressure and the crude material was purified by flash column chromatography (hexane$\mathrm{AcOEt})$ to provide the desired product (10a-d) and/or the intrasite by-product $\mathbf{1 1}$.

(E)-Methyl 6-phenylhex-4-enoate (10a). ${ }^{10}{ }^{1} \mathrm{H}$ NMR $\left(\mathrm{CDCl}_{3}, 300 \mathrm{MHz}\right): \delta 7.35-7.12(\mathrm{~m}, 5 \mathrm{H}$, Ar), 5.70-5.45 (m, 2H, vinylics), 3.66 (s, 3H, $\left.\mathrm{CH}_{3} \mathrm{O}-\right), 3.33$ (d, J=6.4 Hz, 2H, benzylic), $2.50-$ 2.30 (m, 4H, H2 \& H3). ${ }^{13} \mathrm{C} \mathrm{NMR}\left(\mathrm{CDCl}_{3}, 75 \mathrm{MHz}\right): \delta 173.9,140.5,130.1,129.4,128.3,128.2$, 125.8, 51.4, 38.8, 33.9, 27.7.

(E)-Methyl 5-(4-(chloromethyl)phenyl)pent-4-enoate (10b). ${ }^{8 \mathrm{~d}}{ }^{1} \mathrm{H} \mathrm{NMR}\left(\mathrm{CDCl}_{3}, 300 \mathrm{MHz}\right): \delta$ 7.38-7.30 (m, 4H, Ar), 6.42 (dt, $J_{l}=15.8 \mathrm{~Hz}, J_{2}=1.3 \mathrm{~Hz}, 1 \mathrm{H}$, vinylic), 6.28-6.16 (m, $1 \mathrm{H}$, vinylic), 4.57 (s, $\left.2 \mathrm{H},-\mathrm{CH}_{2} \mathrm{Cl}\right), 3.69$ (s, 3H, $\left.\mathrm{CH}_{3} \mathrm{O}-\right), 2.60-2.45$ (m, 4H, $\left.\mathrm{H} 2 \& \mathrm{H} 3\right) .{ }^{13} \mathrm{C} \mathrm{NMR}\left(\mathrm{CDCl}_{3}, 75\right.$ $\mathrm{MHz}): \delta \quad 173.3, \quad 137.6,136.2,130.4,129.3,128.8, \quad 126.4, \quad 51.6, \quad 46.1,33.7,28.2$. IR (film): $v_{\max }\left(\mathrm{cm}^{-1}\right)$ 2922, 1737 (CO), 1436, 1263, 1161. HRMS m/z 239.0840 [(M + H $\left.\mathrm{H}^{+}\right)$; calcd for $\mathrm{C}_{13} \mathrm{H}_{16} \mathrm{ClO}_{2}$ : 239.0833]

(E)-Methyl 5-(2-bromophenyl)pent-4-enoate (10c). ${ }^{1} \mathrm{H} \mathrm{NMR}\left(\mathrm{CDCl}_{3}, 300 \mathrm{MHz}\right): \delta 7.52(\mathrm{dd}$, $\left.J_{I}=7.9 \mathrm{~Hz}, J_{2}=0.6 \mathrm{~Hz}, 1 \mathrm{H}, \mathrm{Ar}\right), 7.48\left(\mathrm{dd}, J_{1}=7.7 \mathrm{~Hz}, J_{2}=0.8 \mathrm{~Hz}, 1 \mathrm{H}, \mathrm{Ar}\right), 7.24(\mathrm{~m}, 1 \mathrm{H}, \mathrm{Ar}), 7.06$ (dd, $\left.J_{l}=7.9 \mathrm{~Hz}, J_{2}=1.6 \mathrm{~Hz}, 1 \mathrm{H}, \mathrm{Ar}\right), 6.76\left(\mathrm{~d}, J=15.9 \mathrm{~Hz}, 1 \mathrm{H}\right.$, vinylic), $6.15\left(\mathrm{dd}, J_{l}=15.9 \mathrm{~Hz}\right.$, $J_{2}=6.4 \mathrm{~Hz}, 1 \mathrm{H}$, vinylic), $3.70\left(\mathrm{~s}, 3 \mathrm{H}, \mathrm{CH}_{3} \mathrm{O}-\right), 2.65-2.47(\mathrm{~m}, 4 \mathrm{H}, \mathrm{H} 2 \& \mathrm{H} 3) .{ }^{13} \mathrm{C} \mathrm{NMR}\left(\mathrm{CDCl}_{3}\right.$, $75 \mathrm{MHz}): \delta 173.2,137.1,132.7,131.4,129.8,128.3,127.3,126.8,123.1,51.6,33.5,28.2$. IR (film): $v_{\max }\left(\mathrm{cm}^{-1}\right) 2945,1735$ (CO), 1460, 1278, 1172. HRMS m/z 269.0179 [(M + $\left.\mathrm{H}^{+}\right)$; calcd for $\mathrm{C}_{12} \mathrm{H}_{14} \mathrm{BrO}_{2}$ : 269.0172]

(E)-Dimethyl hex-2-enedioate (10d) ${ }^{8 \mathrm{~d}, 11}{ }^{1} \mathrm{H}$ NMR $\left(\mathrm{CDCl}_{3}, 300 \mathrm{MHz}\right): \delta 6.95\left(\mathrm{dt}, J_{l}=15.6 \mathrm{~Hz}\right.$, $J_{2}=6.6 \mathrm{~Hz}, 1 \mathrm{H}$, vinylic), $5.86\left(\mathrm{dt}, J_{I}=15.6 \mathrm{~Hz}, J_{2}=1.5 \mathrm{~Hz}, 1 \mathrm{H}\right.$, vinylic), $3.73\left(\mathrm{~s}, 3 \mathrm{H}, \mathrm{CH}_{3} \mathrm{O}-\right), 3.69$ 
(s, 3H, CH3O-), 2.60-2.25 (m, 4H, H2 \& H3). ${ }^{13} \mathrm{C} \mathrm{NMR}\left(\mathrm{CDCl}_{3}, 75 \mathrm{MHz}\right): \delta 172.6,166.7$, 146.7, 121.7, 51.7, 51.4, 32.1, 27.1.

(E)-Dimethyl oct-4-enedioate (11). ${ }^{12}{ }^{1} \mathrm{H} \mathrm{NMR}\left(\mathrm{CDCl}_{3}, 300 \mathrm{MHz}\right): \delta 5.50$ (m, 2H, vinylic), 3.67 (s, 6H, $\left.\mathrm{CH}_{3} \mathrm{O}-\right), 2.41-2.25$ (m, 8H, H2, H3, H6 \& H7). ${ }^{13} \mathrm{C} \mathrm{NMR}\left(\mathrm{CDCl}_{3}, 75 \mathrm{MHz}\right): 173.4$, 129.3, 51.4, 33.8, 27.6 .

\section{Acknowledgements}

The authors thank CONICET (Consejo Nacional de Investigaciones Científicas y Técnicas Argentina), Agencia Nacional de Promoción Científica y Tecnológica (Argentina); Universidad Nacional de Rosario (Argentina) and Fundación Prats (Argentina) for financial support. A.A.P.P. thanks CONICET for fellowship.

\section{References}

1. (a) Seneci, P. Solid-phase Synthesis and Combinatorial Technologies; Wiley \& Sons: New York, 2000. (b) Handbook of Combinatorial Chemistry; Nicolaou, K. C.; Hanko, R.; Hartwig, W., Eds.; Wiley-VCH: Weinheim, 2002. (c) Combinatorial Synthesis of Natural Product-Based Libraries; Boldi, A.M., Ed.; Taylor \& Francis Group: Boca Raton, FL, 2006. (d) Combinatorial Chemistry: From Theory to Application; Bannwarth, W.; Hinzen, B., Eds.; Wiley-VCH: Weinheim, 2006.

2. (a) Bräse, S.; Kirchhoff, J. H.; Köbberling, J. Tetrahedron 2003, 59, 885. (b) Ljungdahl, N.; Bromfield, K., Kann, K. Top. Curr. Chem. 2007, 278, 89.

3. Chatterjee, A. K.; Choi, T.; Sanders, D. P.; Grubbs, R. H. J. Am. Chem. Soc. 2003, 125, 11360.

4. Cho, J. H.; Kim, B. M. Org. Lett. 2003, 5, 531.

5. Nguyen, S. T.; Grubbs, R. H.; Ziller J. W. J. Am. Chem. Soc. 1993, 115, 9858.

6. (a) Schuster, M.; Pernerstorfer, J.; Blechert, S. Angew. Chem. Int. Ed. 1996, 35, 1979. (b) Breed, P.G.; Ramsden, J.A.; Brown, J.M. Can. J. Chem. 2001, 79, 1049.

7. (a) Scholl, M.; Ding, S.; Lee, C. W.; Grubbs, R. H. Org. Lett. 1999, 1, 953. (b) Kingsbury, J. S.; Harrity, J. P. A.; Bonitatebus, P. J., Jr.; Hoveyda, A. H. J. Am. Chem. Soc. 1999, 121, 791. (c) Garber, S. B.; Kingsbury, J. S.; Gray, B. L.; Hoveyda, A. H. J. Am. Chem. Soc. 2000, 122, 8168. (d) Gillingham, D. G.; Kataoka, O.; Garber, S. B.; Hoveyda, A. H. J. Am. Chem. Soc. 2004, 126, 12288.

8. (a) Chang, S.; Na, Y.; Shin, H. J.; Choi, E.; Jeong, L. S. Tetrahedron Lett. 2002, 43, 7445. (b) Testero, S. A.; Mata E. G. Org. Lett. 2006, 8, 4783. (c) Garner, A. L.; Koide, K. Org. Lett. 2007, 9, 5235. (d) Poeylaut-Palena, A. A.; Testero, S. A.; Mata E. G. J. Org. Chem. 2008, 73, 2024. 
9. Being an open vessel system, the influence of the ethylene formed is negligible.

10. Wang, Z. X; Tu, Y.; Frohn, M.; Zhang, J. R.; Shi, Y. J. Am. Chem. Soc. 1997, 119, 11224.

11. Alibes, R.; Blanco, P.; Casas, E.; Closa, M.; de March, P.; Figueredo, M.; Font, J.; Sanfeliu, E.; Alvarez-Larena, A. J. Org. Chem. 2005, 70, 3157.

12. Fyvie, W. S.; Peczuh, M.W. J. Org. Chem. 2008, 73, 3626. 